\title{
A sociedade da informação e a infoexclusão
}

\begin{abstract}
Rodrigo Baggio
Autodidata e empreendedor social, fundador e diretor executivo do Comitê para Democratização da Informática. Idealizou há alguns anos um projeto em que as pessoas de menor poder aquisitivo discutiam sua realidade e buscavam soluções a partir de tecnologias de informação. Iniciou uma campanha junto a empresas de computadores para criar escolas de informática em favelas.

Após uma palestra em Seatlle, Estados Unidos, conseguiu o apoio do pai de Bill Gates. Um dos seus lemas define suas idéias inovadoras: "É preciso diminuir o apartheid digital".
\end{abstract}

\section{Resumo}

Em plena Era da informação, é fundamental que se democratizem as ferramentas tecnológicas, um dos principais requisitos do novo mercado de trabalho, para que os novos recursos de comunicação e tecnologia não se transformem em um fator de aprofundamento de exclusão social. O Comitê para

Democratização da Informática luta contra esse apartheid digital, desde que, há 5 anos, começou a promover a troca de idéias entre moradores de comunidades carentes no Rio de Janeiro e a arrecadação de computadores para realizar essa empreitada. Assim nasceu a primeira Escola de Informática e Cidadania (EIC) no morro Santa Marta. Hoje, já com o status de ONG, o CDI implanta seu modelo em várias comunidades do Brasil e do mundo, sempre replicando sua metodologia de estimular as EICs a buscar a sustentabilidade, além de dar apoio pedagógico, material e de manutenção. Para realizar essa missão, o comitê conta com a colaboração financeira de diversos parceiros dos setores privado e público, um esforço que já produziu histórias de sucesso para muitas pessoas, cujas vidas foram diretamente beneficiadas pela informática e seus recursos.

\section{Palavras-chave}

Cidadania; Infoexclusão; Apartheid digital; Alfabetização digital; Inclusão social; Democratização da informática.

\section{Information society and infoexclusion}

\begin{abstract}
Right in the information Era, it is fundamental that the technological tools be democratized, one of the main requirements for the new labor market, so that the new communication and technology resources will not turn into a factor of plunging into social exclusion. The Committee for Informatics Democratization (CDI) has been fighting against this digital Apartheid since five years ago, when it started to promote the exchange of ideas among the needy dwellers and communities in Rio de Janeiro, as well as the campaign for acquisiton of computers to carry out this task. That is how the first Informatics School and Citizenship (EIC) was born in Santa Marta. Today, having already the NGO status, the CDI implants its model in several communities in Brazil and around the world, always applying the same methodology to stimulate the EICs to seek sustainability, in addition to supplying pedagogical support, material and maintenance. In order to achieve this mission, the Committe counts on a funding cooperation of different partners from the private and public sectors, an effort which has yielded stories of great success for a lot of people, whose lives were directly improved by informatics and its resources.
\end{abstract}

\section{Keywords}

Citizenship; Infoexclusion; Digital apartheid; Digital literacy; Social inclusion; Informatics democratization.

\section{INTRODUÇÃO}

O ingresso da humanidade na Era da Informação é um fato, mas ainda apenas para uma pequena parcela da população. As novas tecnologias, em particular a Internet, vieram para ficar e já começaram a alterar o comportamento da sociedade - como um dia fizeram o telefone, o rádio e a TV. Há 100 anos, ninguém imaginava que o desenvolvimento tecnológico nos daria a alcunha de Sociedade da Informação. Agora temos uma infinidade de soluções digitais cada dia mais surpreendentes e avançadas. Entretanto, devemos estar atentos para não nos iludirmos confundindo progresso com pirotecnia. Se esse conhecimento acumulado não for compartilhado pela sociedade como um todo, corremos o risco de ratificarmos o abismo que separa os ricos dos pobres.

Segundo dados do IBGE, o Brasil tem hoje 20 milhões de pessoas incapazes de ler e escrever. Entretanto, ainda não se sabe quantos são os analfabetos digitais, aquela categoria de pessoas despreparadas para viver a interação com as máquinas. A precariedade de condições a que essas pessoas estão submetidas colocam-nas também, muito provavelmente, integrando os índices do desemprego e do trabalho informal, crescentes em nossa realidade.

A nova divisão internacional do trabalho, por outro lado, reflete uma reestruturação do processo produtivo, e novos postos e perfis profissionais são exigidos. $O$ novo trabalhador deve ser um sujeito com permanente capacidade de aprendizagem e de adaptação a mudanças, deve saber trabalhar em grupo, de preferência em equipes multidisciplinares, e ter domínio da linguagem das máquinas. Ou seja: deve também ser alfabetizado do ponto de vista digital.

Assim, o mundo da tecnologia também se configura como uma forma de inclusão social. A aprendizagem da informática e o acesso às novas linguagens de comunicação e informação não só possibilitam oportunidades econômicas, de geração de renda, como também representam um importante capital social. A informática também representa uma atração irresistível para os jovens que vivem em comunidades pobres. Aliada ao aprendizado de noções de direitos humanos e ecologia, então, criam-se maiores oportunidades para as crianças e adolescentes, beneficiando, simultaneamente, as suas famílias e comunidades. 


\section{O Comitê para democratização da informática}

Somos uma organização não governamental, sem fins lucrativos, que desenvolve, desde 1995, o trabalho pioneiro de levar a informática às populações menos favorecidas. Como resultado dos esforços da organização, já capacitamos, no total, mais de 48.000 crianças e jovens. Implementamos programas socioeducacionais com 188 Escolas de Informática e Cidadania (EIC) em 17 estados no Brasil. Nosso modelo foi considerado exemplar e inovador por organizações como BID, Bird e Unesco, e está presente em mais quatro países: Japão, Uruguai, Colômbia e México.

O objetivo da organização é dar acesso às tecnologias de informação aos membros de comunidades pobres, principalmente crianças e jovens, além de cegos, doentes mentais, deficientes físicos, presos e minorias étnicas, promovendo também a cidadania, alfabetização, ecologia, saúde, direitos humanos e não-violência.

\section{O começo do trabalho}

Em 1993, foi criada a Jovemlink, um serviço de boletim on-line (BBS) que buscava dar aos jovens das comunidades de baixo poder aquisitivo a oportunidade de debater assuntos como meio ambiente, direitos humanos e cidadania. A idéia era, literalmente, fruto de um sonho que eu tivera e que me deixou muito impressionado. Nesse sonho, eu via jovens e crianças pobres usando o computador para discutir seus problemas.

O início não foi fácil. Após um tempo de trabalho, notei que as favelas para as quais o projeto era direcionado não participavam ativamente da idéia, pois não possuíam os equipamentos necessários para ter acesso à BBS. Após uma mobilização de voluntários interessados na causa e com apoio de organizações como o IBASE e Viva Rio, decidimos oferecer um espaço aos moradores de comunidades, onde eles pudessem não somente ter o acesso, mas também aprender e utilizar a informática de modo qualificado.

Esta idéia começou a ser colocada em prática com a campanha "Informática para Todos" que recolheu computadores usados e os repassou para os centros comunitários. Entretanto, mais uma dificuldade foi encontrada: os equipamentos doados apresentavam defeitos com freqüência e eram conseqüentemente inutilizados. Nessa época, comecei a ensinar manutenção de computadores. A idéia gerou um interesse considerável, e mais donativos chegaram com o resultado da criação da primeira Escola da Informática e Cidadania (EIC) no Rio, em março de 1995, na favela Santa Marta, fruto de uma parceria com o Grupo Eco-organização comunitária local. Em conseqüência da grande repercussão do fato na mídia, o Comitê para Democratização da Informática (CDI) foi fundado no final de março de 1995 e, em novembro do mesmo ano, adquiriu a categoria de ONG.

\section{Replicando o modelo: gestão e sustentabilidade}

Escolas de Informática e Cidadania (EICs) - O CDI investe na capacidade das próprias comunidades de realizar os seus empreendimentos socioeducacionais. Nossa principal atividade é a implantação de Escolas de Informática e Cidadania (EICs) em comunidades pobres, oferecendo gratuitamente subsídios para montar sua infraestrutura com equipamentos doados por empresas e sistematizar estratégias pedagógicas e administrativas através da capacitação dos instrutores de informática (membros da própria comunidade) e de encontros periódicos com os coordenadores das EICs (membros da entidade parceira). Uma vez criada uma EIC, o CDI se compromete a acompanhá-la no seu desenvolvimento, identificando demandas, dificuldades e sugestões, mantendo sempre, portanto, o estímulo à busca de soluções dos problemas pelas próprias comunidades.

Rede CDI - O modelo desenvolvido pelo CDI tem sido tão bem-sucedido que pessoas de diversos cantos do Brasil e do mundo procuram a sede nacional, dispostos a implementar EICs em suas comunidades e países. Contudo, a implementação de uma EIC, por si só, não é suficiente para seu sucesso. É fundamental que exista um grupo organizado que possa fazer contatos com organizações que irão, efetivamente, montar as escolas; organizar campanhas para arrecadar equipamentos e fundos para viabilizar projetos; dar suporte técnico, pedagógico e metodológico às EICs, incluindo a capacitação dos futuros instrutores. Este grupo é o que chamamos de um CDI Regional ou Internacional. Atualmente, existem 23 CDIs Regionais e 4 Internacionais. Cada CDI é formado, inicialmente, por uma equipe de voluntários (pessoas dispostas a lutar pela democratização da informática) que cumpre as três funções acima mencionadas. Este grupo requer um perfil que o qualifique para cumprir estas funções. É importante a presença de pessoas que tenham experiência com comunidades e organizações não governamentais para viabilizar as parcerias, técnicos em software e hardware para montar e instalar os computadores, pessoas com formação pedagógica e noções de cultura digital para ensinar os futuros instrutores das EICs e, por fim, pessoas que possam articular campanhas de arrecadação de equipamento e 
solicitar o apoio de empresários, companhias e outras instituições. Eventualmente, um CDI pode até tornar-se juridicamente uma organização não governamental. Foi isso que aconteceu com o CDI-RJ (hoje, CDI Nacional), o que possibilitou a arrecadação de verbas e formação de parcerias com diversas fundações para formar uma equipe de profissionais que se dedicam unicamente à democratização da informática. A Rede CDI conta com o apoio institucional do CDI-RJ para viabilizar seus projetos. A equipe CDI-RJ está trabalhando para auxiliar todos os CDIs por meio de novos canais de comunicação, novos materiais didáticos e campanhas de arrecadação de equipamentos e verbas.

\section{Cidades onde o CDI está presente:}

1. Rio de Janeiro

2. Petrópolis

3. Maceió

4. Salvador

5. Fortaleza

6. Recife

7. Brasília (DF)

8. Vitória

9. Campo Grande

10. Além Paraíba (MG)

11. Belo Horizonte

12. Juiz de Fora

13. Varginha

14. Belém

15. Curitiba

16. Porto Alegre

17. Blumenau

18. Florianópolis

19. Campinas

20. Piracicaba

21. São Paulo (Capital)

22. Aracaju

23. Goiânia

Países onde o CDI está presente:
1. Japão
2. Uruguai
3. Colômbia
4. México

\section{A proposta político-pedagógica e a metodologia de ensino CDI}

Finalizamos no mês de setembro, em uma parceria com o NIED - Núcleo de Informática Aplicada à Educação da Unicamp, a sistematização do material pedagógico aplicado nas Escolas de Informática e Cidadania. Após vários meses de observações, discussões, estudos e reflexões coletivas, compilamos os resultados de cinco anos de trabalho em uma proposta político-pedagógica e na metodologia de ensino da informática e conteúdos de cidadania. Estamos cada vez mais convencidos de que chamar a atenção para o desenvolvimento de temas sociais é um dos diferenciais relevantes de nosso trabalho.

No CDI, entendemos que as ações que se desenvolvem dentro das instituições educacionais - sejam escolas, sindicatos, igrejas, ongs - são parte de um processo social mais amplo e refletem, em sua organização, características presentes na sociedade. Assim sendo, as ações que se desenvolvem dentro dessas instituições devem ser analisadas na relação que estabelecem com o contexto sociopolítico maior. Não adianta estruturar uma nova proposta político-pedagógica, um novo planejamento destinado a produzir mudanças e criar uma consciência crítica, se não houver integração entre essa consciência crítica, os processos sociais, principalmente a prática educativa e a prática social.

\section{Rede de parceiros: compromisso e envolvimento}

A implementação dos projetos socioeducativos do CDI é viabilizada, além das parcerias com a comunidade para implantação de Escolas de Informática e Cidadania, através da interlocução que a organização realiza com iniciativas do setor privado, de diversas organizações filantrópicas, além de parcerias com o Estado. Esses apoios variam de acordo com o estado onde está implantado o projeto. São doações de recursos financeiros e materiais. Para se Ter uma idéia, foi realizada este ano a Campanha Megajuda, em parceria com a Câmara Americana de Comércio, na qual arrecadamos 930 computadores. Quanto aos recursos financeiros, dados de nosso relatório de atividades em 1999 apontavam que $58 \%$ dos investimentos eram realizados por Institutos e Fundações filantrópicas e 38\% por empresas. Este ano tivemos um aumento no número de parcerias com empresas pulverizando um pouco mais a natureza dos nossos recursos. Vale destacar também um grande projeto firmado com o BNDES. 
Alguns indicadores do trabalho realizado: avaliação externa confirma impacto do modelo

Em 1999, contratamos uma equipe da conceituada organização Instituto de Estudos da Religião, para elaboração de um plano de estudo sobre o processo de implantação do CDI, enfocando diversos aspectos da sua missão junto a alunos, instrutores, entidades locais e as comunidades em que as escolas operam. Este ano, pudemos ter contato com a avaliação já concluída, com uma visão bastante interessante do impacto institucional em diversos planos. Dos indicadores que resultaram desse material, tem destaque o perfil de alunos do CDI. Tomados em conjunto, os alunos das Escolas de Informática e Cidadania podem ser caracterizados por:

- serem jovens e adolescentes - $64,5 \%$ entre 10 e 18 anos, com concentração entre 13 e 18 anos (48\%);

- distribuídos equilibradamente por sexo, com pequena vantagem para o grupo feminino $(55,7 \%)$ em relação ao masculino $(44,3 \%)$;

- com escolaridade entre a $5^{\mathrm{a}}$ e $8^{\mathrm{a}}$ série do ensino fundamental (46,3\%);

- predominantemente de cor morena (41\%);

- definidos como de religião católica (46\%);

- moradores das Zonas Norte e Oeste (41,6\%);

- maciçamente estudantes $(72,3 \%)$ de escolas públicas (82\%) estudando diurnamente $(88,5 \%)$.

Com relação ao sexo, diferentemente do que se poderia pensar na informática como uma área de maior interesse dos rapazes, os dados mostram um crescente interesse feminino. De acordo com a faixa de idade, o CDI possui um grupo de alunos crianças de até 12 anos (19,3\%), outro, adolescente (entre 13 e 18 anos de 48,3\%) e uma faixa de adultos (acima de 25 anos de 23,7\%), que configuram interesse e expectativas específicas, gerando, obviamente, necessidades diferenciadas em relação a seu ensino.

\section{Os alunos e suas famílias}

Com relação aos grupos domésticos nos quais estão inseridos os alunos das escolas do CDI, há dados extremamente reveladores da constituição das famílias populares urbanas no Brasil. Isto significa não só a presença de uma multiplicidade de arranjos familiares, como significativa presença de grupos domésticos com diferentes tipos de parentes e agregados, além da importância dos lares chefiados por mulheres.

Considerando as estruturas familiares, observa-se que:

- $43 \%$ dos alunos vivem com suas famílias de origem com a presença dos pais e irmãos.

- $27 \%$ dos alunos vivem em estruturas familiares chefiadas por mulheres, sem a presença do pai. Esse percentual de famílias chefiadas por mulheres corresponde à média existente no Brasil - em torno de 25\%, segundo PNAD (1998). O que os dados igualmente mostram é que se trata de famílias mais vulneráveis a situações de pobreza. Essa vulnerabilidade tem como resultado a estratégia familiar de inclusão de agregados com a presença dos quais as famílias se fortificam.

- $18 \%$ dos alunos vivem em famílias por eles constituídas, sejam reduzidas ao aluno (a) e seu cônjuge; ao aluno com seu cônjuge e filhos ou com outros agregados - normalmente sogros, cunhados e sobrinhos.

- $13 \%$ vivem em famílias marcadas por outros tipos de relações de consangüinidade e afinidade. São aqueles que vivem com avós, tios, padrinhos, colegas ou vizinhos, sem a presença dos pais ou cônjuges.

\section{Composição Familiar}

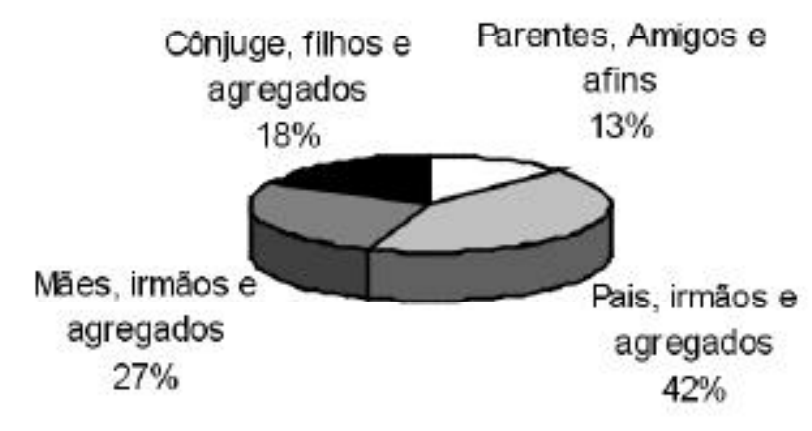


Histórias que alimentam o sonho: exemplos de sucesso na história do CDI

Ainda segundo a avaliação de impacto, As Escolas de Informática e Cidadania constituem, para a maioria dos alunos, sua primeira experiência de formação em informática. Anteriormente à entrada na EIC, a maioria (74\%) não havia feito nenhum curso. Na verdade, há entre os alunos uma consciência de que hoje grande parte do acesso aos empregos tem colocado o domínio da informática como um de seus critérios seletivos. Evidentemente que esse domínio é elemento necessário, mas não suficiente. Inclusive, os que tentaram emprego identificaram uma enorme diversidade de obstáculos, além da falta de qualificação em informática. A maioria dos alunos $(86,5 \%)$ considera que o curso mudou aspectos de sua vida. De um modo geral, os alunos indicaram mais de uma mudança Os dois maiores impactos foram na área da sociabilidade e da descoberta de novas habilidades e interesses não desenvolvidos pela escola formal.

A revista Veja Rio publicou em 17/ 07 / 2000 a matéria Cesta Básica Digital, contando algumas histórias exemplares, as quais descrevo abaixo, resultados do trabalho desenvolvido pelo Comitê para Democratização da Informática. A modificação nessas vidas é a realização daquele sonho que eu tive há mais de cinco anos e confirma o verso do poeta que disse que "sonho que se sonha só é só um sonho, sonho que se sonha junto é realidade”.

\section{Valter Rodrigues Rosa 48 anos}

Valter Rodrigues Rosa, de 48 anos, paciente do hospital, é um dos 20 alunos do curso. Ele já aprendeu noções básicas de computação e se diverte criando desenhos coloridíssimos na tela. "É bom aprender sempre. Nós não estamos na era da informática?", pergunta ele, que planeja fazer cartões para vender. Colega de Valter no curso, Orlando Varella Júnior, 28 anos, também mostra entusiasmo com as novas descobertas traçadas pelo mouse. "No início, achei meio difícil, mas a gente consegue aprender", diz o rapaz, que faz tratamento no Pinel há quatro anos.

\section{Romildo Gonçalves Neto 18 anos}

Graças às parcerias, Romildo Gonçalves Neto, de 18 anos, que vivia abrigado em uma casa para meninos de rua na Tijuca, descobriu o mundo sem limites da internet. Aprendeu informática em uma escola do CDI e chegou a estagiar no site Cadê. Hoje trabalha em projetos do Comitê, ganha uma bolsa-auxílio, mora com o pai e voltou a freqüentar o supletivo. "Meu forte era a capoeira. Não achava que informática fosse para mim." Quando concluir o 2o grau, Romildo já sabe: vai fazer vestibular para análise de sistemas.

\section{Luiz Cláudio Lino 22 anos}

Depois de anos em uma loja de materiais de construção, Luiz Cláudio Lino, 22 anos, viu sua vida mudar na semana passada. O curso de informática no Dona Marta serviu de passaporte para a vaga de office-boy no escritório do site de trocas no.money. "Nós o escolhemos porque sabemos que o curso é sério e precisamos de alguém que conheça os termos usados na informática”, diz Liora Rubin, gerente de marketing do site.

\section{Max Freitas \\ 16 anos}

Além de ensinar e dar oportunidades de emprego, os cursos do CDI despertam vocações. Morador do Morro da Mangueira, Max Freitas virou fera na informática. Mas se encantou mesmo com o lado social do projeto. Aos 16 anos, foi eleito um dos 2.000 Jovens Sonhadores do Milênio, em um projeto que uniu a Unesco, a Disney e o McDonald's. Estagiou em vários sites e sonha levar a oportunidade que teve ao maior número possível de jovens carentes. "O filho do rico já cresce vendo computador. $\mathrm{O}$ filho do pobre, não. É muito mais difícil para ele porque falta oportunidade", discursa. 
Altamiro Serra

34 anos

Cercado pelas grades da Penitenciária Lemos de Brito, o ex-metalúrgico Altamiro Serra, de 34 anos, condenado a 12 anos de prisão por seqüestro, jamais imaginou que poderia encontrar futuro no confinamento. Até chegar à cadeia, nunca havia posto as mãos em um computador. "Tinha até medo", confessa. Venceu o temor, fez o curso e tornou-se instrutor. Suas lições de informática já diplomaram dezenas de outros presos, dezoito guardas e nada menos que dois diretores da penitenciária. "O computador não é nenhum bonequinho de louça. Só é preciso falar o idioma dele", afirma. À espera da liberdade condicional, ele já sabe o que fazer quando sair. "Vou trabalhar nessa área." Não é o único. Hélio Bittencourt, de 33 anos, sonha ensinar crianças carentes. Arthur White Alvarenga, de 38, planeja abrir um cyber café.
Josefa Geralda da Silva 41 anos

A empregada doméstica Josefa Geralda da Silva, a "Detinha", 41 anos, foi uma das primeiras alunas do curso na favela Júlio Otoni, em Santa Teresa. "Achava que nunca ia conseguir mexer em um computador. Fiquei emocionada na primeira vez", recorda. Motivada, Detinha voltou a estudar e agora cursa a $3^{\underline{a}}$ série primária em um colégio do Largo do Machado. A informática também ajudou a alavancar as vendas de doces e salgados que faz para fora. "Fiz uns cartões, espalhei na favela e dei aos amigos. Volta e meia, aparece um cliente", diz. Hoje, na casa de alvenaria de apenas um quarto, a geladeira antiga, o fogão e a TV dividem espaço com um PC 386 usado. "Quando comprei o micro, o HD (disco em que são armazenados os programas) era de 120. Não dava para nada. Troquei por um de 540", conta a doméstica, mostrando intimidade com o vocabulário digital. $\mathrm{O}$ computador, Detinha está pagando em oito vezes. 